\title{
China-Japan-Korea FTA: A Dual Track Approach to a Trilateral Agreement
}

\author{
Srinivasa Madhur
}

Cambodia Development Resource Institute(CDRI), Phnom Penh, Cambodia

\begin{abstract}
This paper argues that a China-Japan-Korea Free Trade Agreement (CJK FTA) will have large benefits to the three Northeast Asian countries and significant implications for global multilateral trade. However, several hurdles seem to make an expeditious completion of a CJK FTA, or even bilateral FTAs between Japan and China or between Japan and Korea extremely difficult. Thus, a pragmatic approach would be to follow a dual-track approach in which China and Korea fast-track the completion of a bilateral FTA between them and the three countries continue their negotiations for a trilateral FTA on a steady track. Neither of these attempts should, however, deter these countries from joining the larger multilateral deals they are pursuing such as the Regional Comprehensive Economic Partnership (RCEP) or the Transpacific Partnership (TPP).
\end{abstract}

\section{JEL Classifications: F15}

Key words: Free Trade Agreements, Preferential Trade Agreements, Regionalism, Multilateralism

\footnotetext{
* Corresponding Author: Srinivasa Madhur; Cambodia Development Resource Institute (CDRI), 56, Street 315, Tuol Kork, P.O. Box 622, Phnom Penh, Cambodia; Tel: +855 238881701, Fax: +855 23880734, E-mail: srini@cdri.org.kh, srinimadhur@gmail.com.

Acknowledgements: This is a substantially revised version of a draft that was prepared when the author was a visiting professor at the Graduate School of International Studies in Seoul National University (SNU), Seoul in 2011. The views expressed here are those of the author and not necessarily of SNU or CDRI. The author would like to thank an anonymous referee of this journal for useful suggestions for revision and Socheath Eng for help with data.
} 


\section{Introduction}

Efforts at promoting trilateral economic cooperation among China, Japan, and Korea (CJK) are now more than a decade old. In 1999, the heads of state from these three Northeast Asian countries agreed to hold yearly summits (trilateral summits) on the sidelines of the ASEAN +3 (Association of South East Asian Nations plus Three) summits. In the initial years of its inception, the trilateral summit constituted a little more than an informal breakfast meeting (Rathus, 2010). The years between 2002 and 2009, in many ways, constituted a long warmingup period for the trilateral economic cooperation, with the three countries conducting several rounds of unofficial studies on the pros and cons of a CJK FTA.

The idea of a CJK FTA received an impetus in 2009 when the then Japanese Prime Minister-Yukio Hatoyama-proposed that the trilateral FTA be subject to an official study. The official study that was subsequently started in May 2010 and was to be originally completed by 2012 represented the first concrete step towards stronger economic cooperation in Northeast Asia. In the May 2011 trilateral summit held in Tokyo, the three countries decided to advance the deadline for the completion of the official study from 2012 to 2011. Subsequently, at the fifth trilateral summit meeting held in May 2012, the leaders of the three countries announced that the CJK FTA talks would be launched within the year so that the preparatory work for the long-pending project could start immediately afterwards. Following up on that announcement, the three countries held the first round of trilateral negotiations in March 2013 and another two rounds of official negotiations are scheduled for the remaining months of 2013.

The recent decision to step up the efforts for a CJK FTA comes on the heels of the ASEAN+3 Countries (the 10 Association of Southeast Asian Nations [ASEAN] plus China, Japan, and Korea) successfully (i) multilateralizing the Chiang Mai Initiative and establishing the $\$ 240$ billion regional reserve fund (ii) setting up the ASEAN+3 Macroeconomic Research Office (AMRO) (iii) creating a Credit Guarantee and Investment Facility (CGIF as part of the Asian Bond Markets Initiative or ABMI). The benefits from these initiatives in monetary and financial cooperation can be enhanced if the region could complement them with effective cooperation in trade and investment. CJK FTA could be the next step in that direction, as these three countries account for a substantial part of the ASEAN+3 trade and investment flows. It is thus an opportune time for the three Northeast Asian countries to take up the proposal of a CJK FTA more seriously than they had in the past.

At the regional level, a CJK FTA has the potential to become the backbone of a more multilateral, region-wide FTA in East Asia initially and more generally in Asia. The formation of a region-wide FTA in Asia is a key recommendation that has been made by recent studies on Asian economic integration (ADB, 2008a and 2011). Such a region-wide FTA could also enable Asian countries to gradually speak up with unified positions on international trade and investment in global forums and institutions that are responsible for global economic 
governance (Madhur, 2012a and 2012b).

Against the above backdrop, this paper first analyses the implications of a CJK FTA from a regional and global multilateral perspective in Section II. It then looks at the CJK FTA from the perspectives of the three member countries involved - China, Japan, and Korea in Section III. Given the inherent difficulties in completing a trilateral FTA such as the CJK FTA discussed in Section III, Section IV explores the options of using bilateral FTAs among the three countries as a route to an eventual trilateral or the CJK FTA. Section V pulls together the analysis of the previous sections and proposes a dual-track approach in which China and Korea fast-track the completion of a bilateral FTA between them, while the three countries proceed on a steady track in bringing to fruition, the potentially more beneficial but much more complex and timeconsuming trilateral FTA.

\section{CJK FTA from a Multilateral Perspective}

A CJK FTA is part of a major trend in global trade over the past two decades-formation of what the World Trade Organization (WTO) generically refers to as preferential trade agreements (PTAs). In 1990, there were about 60 PTAs in the world but by 2010 that number increased to close to 300 with about half of them being regional trade agreements (RTAs) in that their member countries belong to the same region, while the remaining PTAs are nonregional i.e., involving member countries from more than one geographical region (WTO, 2011, p. 58). On the average, a WTO member country now has about 15 PTAs. The increase in the number of PTAs has led to an increase in the share of intra-PTA trade in world trade. One estimate shows that between 1990 and 2008, that share increased from 28\% to 50\% (including the European Union, EU) and from 18\% to 35\% (excluding the EU) (WTO, 2011, pp. 64 and 72). Within this envelope, the share of intra-PTA trade conducted at preferential tariffs is lower at about $30 \%$ including EU and about 16\% excluding the EU (WTO, 2011, p. 73).

Irrespective of the exact number of PTAs and the precise share of world trade routed through them, trade theorists view them as a disruptive deviation from the ideal world of multilateral free trade. PTAs are, therefore, considered as second bests compared to the first best of multilateral free trade. The CJK FTA is not an exception to such a criticism (Krishna, 2012 for a recent exposition of the criticism of PTAs). The real world is, however, less pure than what the pure trade theorists would like it to be. Hence, even the WTO (or its predecessor, the General Agreement on Tariffs and Trade, GATT), which is the global institution that is responsible for governing world trade, makes provisions for the formation of PTAs within its overall framework of multilateral free trade subject to a couple of conditions. Such provisions are stipulated in GATT's well-known Article XXIV. In addition, there is an enabling clauseClause V - that allows PTAs but only among developing countries. Hence, although PTAs are 
second bests compared to the ideal of multilateral free trade envisaged by the trade theorists, they are still compatible with the WTO. Studies examining the WTO-compatibility of PTAs are not many, partly because of the ambiguities surrounding the Article XXIV condition of "substantially all trade" that has to be covered by PTAs (Scollay and Grynberg, 2005; Crawford and Lim, 2011; Hamanaka, 2012).

Even going beyond the WTO-compatibility of the PTAs, recent empirical studies have allayed some of the worst fears of trade theorists about PTAs (Freund and Ornelas, 2010; Anderson and Yotovo, 2011). After surveying empirical evidences on the effects of several PTAs, one of these studies comes to the conclusion: "Empirically, neither widespread trade diversion nor stalled external liberalization has materialized, while the undermining of multilateralism has not been tested" (Freund and Ornelas, 2010, p. 1). According to Freund and Ornelas (2010, p. 4), "The direst predictions of RTAs - that they will generate significant trade diversion and erode the world trade system - have not come to pass. RTAs have been the main instrument behind reciprocal liberalization in recent years, and the evidence on trade creation and RTAs facilitating external trade liberalization is encouraging." Indeed the same study highlights that trade creation, not trade diversion, is the norm for PTAs (p. 42). Similarly, another empirical study finds that the FTAs delivered significant benefits to their members while only negligibly harming non-members (Anderson and Yotov, 2011, p. 1 and p. 31).

It is no surprise, therefore, that countries are increasingly relying on PTAs as their preferred method of achieving reciprocal trade and investment liberalization. "Slow multilateralism" at which the WTO-led trade negotiations often proceed has indeed contributed to that preference. In large part, "slow multilateralism" has been due to: (i) the expansion of the agenda of the WTO-led negotiations to a variety of issues that goes far beyond the governance of a rulebased global system of trade in goods and services which is WTO's core mandate (ii) WTO's ultra-legalistic dispute settlement mechanism (iii) WTO's article on anti-dumping measures that gives too many excuses for member countries to resort to protectionist measures resulting in undue delays (Srinivasan, 2004 and Madhur, 2012a). Overall, there is huge merit in limiting the jurisdiction of the WTO to its core mandate and rescuing the organization from becoming a "world bargaining organization" (WBO to wit) on anything and everything (Srinivasan, 2004). In addition to "slow multilateralism," other factors have also been at work behind the growing number of PTAs globally; the phenomenon of natural trading partners, efforts at deeper integration, and the presence of domino effects being the most important of them.

Neighboring countries that already trade heavily among them tend to form PTAs as they have much to gain by their low natural trade (including transport) costs. Such PTAs by their very nature are likely to lead to trade creation rather than trade diversion (Wonnacott and Lutz, 1989 and Krugman, 1991). More broadly, countries closer to each other in terms of distance and pairs of countries with huge complementarities and even similar economic sizes tend to form PTAs than countries that do not share these characteristics (Bergstrand et al., 2009 and WTO, 2011). Looking at the evidence on this issue, one recent study comes to this conclusion: 
"Proving that agreements are natural or unnatural is daunting as it requires an assessment of many potential agreements and their welfare consequence... Nevertheless, there is solid empirical support for the more general premise of the natural trade bloc view, that trade blocs are formed by countries that have a lot to gain from freer trade (Freund and Ornelas, 2010, p. 13).

Another driving force behind PTAs is the higher possibility of pursuing deeper integration that goes beyond mere trade liberalization among a smaller group of countries than at the global multilateral level. That helps members of a PTA to lock in deeper integration, transforming these PTAs into WTO-Plus. Thus, service commitments in many PTAs go well beyond commitments in the General Agreements on Trade in Services as well as the Doha Round offers in services. More and more PTAs include provisions on non-tariff, technical barriers to trade, and countries that share supply chains and production networks tend to enter into deeper integration agreements involving regulatory cooperation and harmonization (WTO, 2011, pp. 11-13). Members of a PTA could thus move "further and faster" through such deeper integration than what is possible through the global multilateral negotiations (WTO, 2011, p. 6).

Finally, domino effects or the formation of a PTA inducing non-members to either join the PTA or to form another PTA have been a key driving force behind the rapid growth of PTAs (Baldwin, 1995 and 2010; WTO, 2011). The latter phenomenon, an existing PTA inducing a subsequent new PTA, is also referred to as "endogenous regionalism" (WTO, 2011, p. 97). Indeed, some attribute much of the spread of regionalism in trade to such domino effects. "Putting it roughly, FTAs are contagious and the degree of contagion is related to the partners' markets" (Baldwin and Jaimovich, 2010, p. 21). Using an empirical measure of such a contagion index, one recent study finds robust empirical evidence for the presence of domino or contagion effects in the past PTAs (Baldwin and Jaimovich, 2010).

Overall, it is reasonable to infer that PTAs have not been as disruptive to multilateralism as trade theorists had previously feared. Indeed, it is possible to view PTAs as building blocks for eventual global multilateral free trade, although how far PTAs could act as such building blocks would very much depend upon the way PTAs are designed and implemented in practice (see ADB, 2008b; Menon, 2009, Freund and Ornelas, 2010; and WTO, 2011 for a discussion of PTA design issues). Reflecting such an assessment of PTAs, the WTO's 2011 report on worldwide PTAs concludes: "An overarching conclusion of this report is that regional and multilateral approaches to trade cooperation need not be incompatible, but neither can they be seen simply as arrangements that serve the same purpose or satisfy the same needs... Support for an increasingly outward-looking and inclusive global trading order has been strong in the period since the end of the Second World War, and this growing trend towards openness has manifested itself through unilateral, bilateral, regional, and multilateral approaches...The sheer number of PTAs and continuing momentum towards establishing more of them suggest that they are here to stay" (WTO, 2011, p. 16).

How does a CJK FTA measure up to the analytical perspectives on PTAs above? A CJK 
FTA shares many of the driving forces that were behind the PTA revolution that continues to sweep the global trade system. In many ways, the three countries share the natural trading partners' features, they are an integral part of the Factory Asia's supply chains and production networks, to varying degrees they show the keenness to go beyond trade and lock in deeper integration measures, and then there are the domino effects of the various FTA negotiations that are underway both at the regional and the trans-regional levels.

The CJK countries account for about $16 \%$ of world trade in goods and services, about $20 \%$ of world GDP and about $22 \%$ of global population (Table 1). They constitute more than $70 \%$ of the ASEAN+3's combined trade in goods and services (Figure 1). They also constitute about $90 \%$ of the ASEAN+3's GDP and about $70 \%$ of its total population. From a purely economic perspective, a CJK FTA could thus become the foundation on which an ASEAN+3 FTA could be built. Encouragingly, ASEAN already has bilateral FTAs with each of the CJK countries. Once a CJK FTA fructifies, it is much easier to consolidate all these bilateral FTAs into a single East Asian FTA. Simultaneously, once an East Asian FTA is in place, a gradual extension of such an FTA to include India could be pursued. The CJK countries now account for more than three-fourth of the economic size of such an extended regional free trade area that encompasses the ASEAN+3 countries and India. Bringing in India to an East Asian FTA could effectively bring a large part of South Asia within the fold of a regional free trade area. Note that India already has a decade-old FTA with Sri Lanka, and that Nepal and Bhutan are economically integrated with India in much more than an FTA sense. Moreover, India already has a comprehensive economic partnership agreement with Korea (effective since January 2010) and a similar agreement with Japan (effective since August 2011). A feasibility study on a China-India FTA has been completed by October 2008, and since China has already become India's largest trading partner, it is only a matter of time for a China-India FTA to come to the negotiating table.

Table 1: Percentage Share of CJK Countries in the World Economy (2010)

\begin{tabular}{|l|c|c|c|}
\hline Country Name & $\begin{array}{c}\text { World Trade } \\
\text { (current US\$) }\end{array}$ & $\begin{array}{c}\text { World GDP } \\
\text { (current US\$) }\end{array}$ & World Population \\
\hline China-Japan-Korea (CJK) & 15.9 & 19.7 & 22.0 \\
\hline China-Korea (CK) & 11.6 & 11.0 & 20.1 \\
\hline China-Japan (CJ) & 13.1 & 18.1 & 21.3 \\
\hline Japan-Korea (JK) & 7.1 & 10.3 & 2.6 \\
\hline China & 8.8 & 9.4 & 19.4 \\
\hline Japan & 4.3 & 8.7 & 1.8 \\
\hline Korea & 2.8 & 1.6 & 0.7 \\
\hline
\end{tabular}

(Source) World Bank, World Development Indicators Dataset, 2012 
Figure 1: Major Asian and Trans-Pacific Multilateral FTAs (\% Share of World Trade in Goods and Services, 2010)

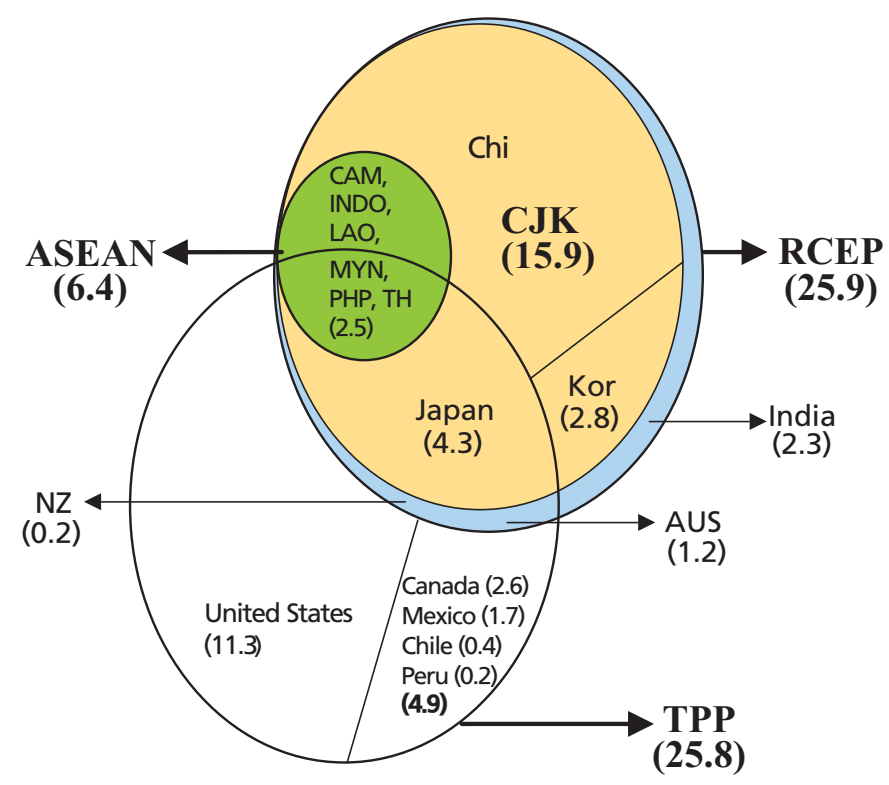

(Notes) AUS: Australia; CAM: Cambodia; INDO: Indonesia; LAO: Laos; MYN: Myanmar; PHP: Philippines; TH: Thailand; BRUNEI: Brunei Darussalam; MAL: Malaysia; SING: Singapore; VNAM: Vietnam; NZ: New Zealand; (1) China-Japan-Korea (CJK) (2) Regional Comprehensive Economic Partnership (RCEP): ASEAN + China, Japan, Korea, India, Australia, New Zealand (3) Transpacific Partnership (TPP): Singapore, Vietnam, Brunei Darussalam, Malaysia, Japan, Australia, New Zealand, United States, Canada, Mexico, Peru, Chile Figures in the brackets are the shares of trade of goods and services in the global total.

(Source) Data on exports of goods and services from the World Bank, World Development Indicators Dataset, 2012

Simultaneously, a CJK FTA could act as a building block for the two major FTAs/ economic partnership agreements that are now being pursued: (i) the Regional Comprehensive Economic Partnership (RECP) Agreement among the 16 countries consisting of the 10 ASEAN countries plus China, Korea, Japan, India, Australia, and New Zealand and (ii) the Transpacific Partnership (TPP) among 12 countries consisting of U.S., Canada, Mexico, Peru, Chile, Brunei, Malaysia, Singapore, Vietnam, Japan, Australia, and New Zealand. Meanwhile, there is also a revival of interest in an APEC FTA among the TPP member countries plus Indonesia, Philippines, Thailand, China, Korea, Hong Kong, Taiwan, Russia, and Papua New Guinea. All these provide even further scope for a CJK FTA to become an enabling factor for multilateral trade and investment liberalization and integration both at the regional and trans-regional levels.

RCEP is primarily an Asian regional cooperation initiative, while the TPP is (as does the APEC) trans-regional in nature in that it involves both Asian and non-Asian countries. Interestingly, both RCEP and TPP cover approximately the same percentage of global trade, 
which is around $26 \%$ (Figure 1). In terms of the negotiation timetable, RCEP is supposed to be completed by the end of 2015 coinciding with the deadline for the beginning of the ASEAN Economic Community, whereas TPP, after having already completed 16 rounds of negotiations, is supposed to be wrapped up by the end of 2013, although that deadline is likely to be extended especially with the recent decision of Japan to join TPP. Within the two groupings, the U.S. is the largest trading country in TPP (with about $11 \%$ of world trade) and China is the largest trading member in the RCEP (with about $9 \%$ of world trade). Although some view the two FTAs as rivals - RCEP as a China-driven initiative and the TPP as a U.S.driven deal - the breadth and depth of the two agendas are quite different from each other and hence the two could also be seen more as complementary to each other (Sim, 2013).

First, RCEP aims primarily at harmonizing existing rules and their application within the various ASEAN FTAs. This is much less ambitious than the TPP's agenda, which covers many issues not covered by the RCEP, such as intellectual property rights, environmental protection, labor, financial services, technical barriers, and other regulatory issues. Secondly, RCEP is mostly focused on measures imposed at the national borders and how to harmonize those measures. TPP, on the other hand, is a much more ambitious negotiation in terms of scope because it covers a wide variety of barriers to trade and investment, which occur beyond national borders.

Overall, since beyond the border issues are necessarily linked to border issues but not necessarily vice versa, countries are better off first addressing the issues involved in the RCEP before joining the TPP. In other words, if a country is not able to deal with the RCEP issues, it will be most unlikely to be able to deal with most of the TPP issues. For example, among other things, it is apprehended that developing countries will not be able to comply with the very high levels of intellectual property rights in the pharmaceutical sector that are being insisted on by the U.S in its TPP negotiations as it would unduly delay the introduction of generic drugs as well as the implementation of affordable public health programs in these countries. Indeed, if the U.S.' position finally prevails in the TPP negotiations, it would force these countries to prioritize intellectual property rights over their much needed public health programs (Gleeson and Friel, 2013). Most developing countries in the RCEP group belong to this category, whereas other countries (such as Japan, Singapore, Australia, and New Zealand) may be able to join both the RCEP and TPP more or less simultaneously. In other words, the former category of countries will have to be "learning to crawl before they walk", while the latter may find it easier to "walk and chew gum at the same time" (Sim, 2013). Either way, the two FTAsRCEP and TPP — need not be competitive but could be complementary to each other, except that countries will have to fulfill the liberalization and harmonization requirements of the kind required by RCEP if they were to be able to negotiate the broader and deeper issues in the TPP agenda.

Only Japan among the CJK countries is currently a member of TPP, although it is possible that Korea may also join it in the near future. It is also possible and even desirable for China to 
be joining TPP in the somewhat distant future (Dalby, 2013). Once that happens CJK could be nested in several of the large regional as well as trans-regional trading arrangements, eventually contributing to global multilateral free trade (Figure 1). Such a dynamic domino effect in PTAs leading to broader multilateral trade and investment liberalization are common in the past. Since the economic size of the CJK countries is substantial, such domino effect could really be significant from the global trade perspective. Thus, along with RCEP and TPP, a CJK FTA could pave the way for open regionalism in Asia.

At the global level, the CJK countries account for about one-fifth of the world's GDP — only a few percentage points lower than the share of the North American Free Trade Area (NAFTA) countries in global GDP (approximately $28 \%$ at market exchange rates). Moreover, a CJK FTA could initiate tariff reductions for an estimated $16 \%$ of global trade in goods and services and a significant portion of foreign direct investment, implying that a CJK FTA could even eclipse the lowering of trade and investment barriers seen by the NAFTA, the European Union, or the ASEAN (Gill, 2012). Overall, therefore, a CJK FTA has perhaps the best prospect of capitalizing on the regional trading arrangements that Asia has been pursuing for more than a decade now.

Some may have apprehensions on the possibilities of such multilateral trade liberalization through the PTA route in the years ahead since the global economy is still struggling to recover from the 2008-09 financial crises. This apprehension could arise from the experience of protectionist measures that countries around the world responded to the 1930s Great Depression. It is natural to think of similar reactions from governments in the years ahead with countries still struggling to get out of the recession and economic slowdown. However, it is important to recognize that the response of countries to the recessions of 2008 2009 in the sphere of trade policy has been very different than during the Great Depression of the 1930s.

During the 1930s depression, the well-known Smoot-Hawley Tariff Act sharply raised U.S tariffs leading to many other countries following it up with similar protectionist measures. In contrast, partly because of the awareness, availability, and willingness of countries to use Keynesian fiscal policy tools to combat recession, protectionist measures have rarely been used to disrupt global trade during the current crisis (Keynes' General Theory was published in 1936 after the 1930s depression). Indeed, revival in global trade is increasingly seen as one of the critical channels for bringing about a faster recovery now (Ruddy, 2010; Eichengreen, 2010; Gadbaw, 2010). Hence, measures to liberalize trade and investment seem to have enough buyin from governments around the world. Given the stalled Doha Development Round, PTAs, whether regional or tarns-regional, have a special and substantial role in that. 


\section{CJK FTA from Members' Perspectives}

That a CJK FTA could become the backbone of a region-wide FTA in Asia or that it could be a building block for broader multilateral trade liberalization are good arguments in favor of such an FTA. However, for this FTA to come to fruition, the three countries involved need to have substantial economic pay-offs and the political will to pursue the project. From a political perspective, a CJK FTA can provide a channel for easing the political tensions in Northeast Asia, which have escalated from time to time in recent years and hence could help bring about the much-needed historical reconciliation among China, Japan, and Korea (KIEP, 2005 and Rana, 2012).

In terms of economic pay-offs, a number of studies - mostly based on simulation of various versions of computable general equilibrium (CGE) models - have estimated the economic benefits of a CJK FTA to the three countries. As expected, these macroeconomic effects depend on a variety of factors such as the structure of the CGE models used, the maintained assumptions of the simulation exercises, and the scope of the FTA coverage (e.g., the length of the negative list) used in the simulation exercises. Generally, simulations using dynamic versions of the CGE models (for example, models incorporating the effects of changes in income on investment and capital accumulation) yield larger effects on GDP than those using static versions. The macroeconomic effects also vary depending on the extent of tariff reductions incorporated in the simulations. Similarly, the estimates are sensitive to whether service trade liberalization is incorporated in the simulation or not.

Subject to these caveats, the various simulation exercises indicate that a CJK FTA would result in higher GDP for all three countries involved: in the range of 0.95 to 5.1 percentage points for Korea, in the range of 0.03 to 1.54 percentage points for China, and in the range of 0.03 to 1.24 percentage points for Japan (Scott and Goodrich, 2001; KIEP, 2005; and Lee, 2006). The simple conclusion to be drawn from these simulation results is that, in broad macroeconomic terms, the three countries would benefit from a CJK FTA individually as well as collectively.

These macroeconomic effects, however, mask the typical differential effects across sectors that an FTA involves. For example, most studies based on simulations of CGE models as well as on sector-wise indicators of revealed comparative advantage come to the general conclusion that a CJK FTA would put pressure on the agriculture and fisheries sectors in Japan and Korea while giving a boost to the higher technology segments of their manufacturing sectors. By the same logic, a CJK FTA would generally benefit China's agriculture and labor-intensive manufacturing but at the same time put competitive pressure on some of its more technologyintensive manufacturing sectors.

Within these overall sectoral impacts, one study (Cheong et al., 2003) came to the conclusion that a CJK FTA would mean that: (i) China's agriculture, processed food, clothing, 
and electronics sectors would benefit while its textile, metals, and automobile sectors would lose (ii) Japan's machinery, automobile, and high-end electronics sectors would benefit whereas its agriculture, fisheries, and clothing sectors would lose (iii) Korea's petrochemicals, textiles, and processed food sectors would benefit while its transportation equipment, automobile, and electronics sectors would lose.

Notwithstanding the need for caution in applying these model-based estimates in real world trade negotiations, such asymmetries in the effects of a trilateral FTA are only natural, given that the three countries differ in their factor endowments, stages of economic development, and technological sophistication. Minimizing the adverse effects and maximizing the beneficial effects is at the heart of trade and investment negotiations, whether through regional or multilateral agreements. At the same time, these asymmetries lead to the emergence of lobbying groups for and against trade and investment agreements within each country, and this poses a major challenge in negotiating such agreements (ADB, 2008b).

Not surprisingly, then, both in Japan and Korea, there is resistance to a CJK FTA from their respective agricultural sector lobbying groups. Perhaps, some of the emerging technologyintensive manufacturing sectors in China would also resist the CJK FTA (as it would put pressure on them to compete with their counterparts in both Japan and Korea), although such lobbying seems to be less vocal than in both Japan and Korea.

There is the additional issue of Japan's preference to treat China as a non-market economy to safeguard against an import surge from China following a CJK FTA and China's reluctance to agree to such a treatment (Kawai and Wignaraja, 2011). Therefore, whatever the overall macroeconomic benefits of a CJK FTA are, its realization is likely to depend on the resolution of several sticky technical issues and an amicable way of managing the various lobbying groups. It is generally presumed that addressing both these challenges would not only be complicated but also a long, drawn-out process, notwithstanding the recent beginning of the negotiations by the three countries. Note that it took about 10 years for the three countries to even agree to start the negotiations, and there is an apprehension that completion of the negotiations may take quite long too. The common interest between the Korean automobile manufacturers and the farmers that has been witnessed in recent months would make it very difficult to hasten the negotiation process.

\section{CJK FTA: A Dual Track Approach}

Based on model-simulation results, it is now generally accepted that the sum of the benefits from three separate bilateral FTAs among China, Japan, and Korea would be less than a single trilateral FTA (KIEP, 2005; Lee 2006). Thus, a trilateral FTA is the most beneficial outcome for the three Northeast Asian countries. However, given the practical difficulties of swiftly 
completing such an FTA, the next best alternative could be to start with bilateral FTAs, even as the trilateral negotiations are pursued slowly and steadily, and eventually consolidating these bilaterals into a single CJK FTA. Such a dual track route may be a more pragmatic approach to better trade and investment cooperation among the three countries. The assumption here is that at least some of the bilateral FTAs may be easier and less time-consuming to put together than the CJK FTA. If the three countries were to pursue such a dual track route, the next obvious question is: Who goes first for the bilateral - China and Japan, China and Korea, or Korea and Japan?

A China-Japan (CJ) FTA would perhaps be the largest bilateral FTA that has yet been put in place. The two countries account for about $13 \%$ of world trade, about $18 \%$ of global output, and about $21 \%$ of global population. Within the CJK block, the two countries account for over $80 \%$ of combined trade and $90 \%$ of combined income (Table 1). Each of the two partners in this bilateral deal would be more or less of equal size in terms of GDP, although Japan is much richer than China. While Japan is an established manufacturing giant both regionally and globally, China is the emerging regional and global manufacturing factory. Within the manufacturing sector, Japan is way ahead in skill and technology-intensive products, while China's strength lies in the more labor-intensive, mass-produced segments. China has a huge comparative advantage in agriculture, while Japan has more developed service sectors. An FTA, then, between Asia's well-established (although somewhat stagnant) economy and its emerging economic powerhouse looks like a very attractive proposition. If implemented, it could have substantial benefits for both partners and would create quite a large trade block, next only to the European Union or NAFTA.

Political hurdles to such a bilateral FTA between the two traditional rivals in Asia may, however, be the most difficult issue to sort out. The sporadic escalation of political tensions between Japan and China in recent years is a testimony to this. Additionally, the sticky issue of Japan's preference to treat China as a non-market economy is not easily resolvable. All this explains why a CJ FTA has not been the subject of even unofficial studies. Overall, therefore, it may perhaps be wishful thinking that such a bilateral FTA can be negotiated and concluded faster than a trilateral CJK FTA. In a CJK FTA, Korea, as the middle-power could at least play the role of mediator and thus could provide a buffer zone between the two traditional Asian rivals.

How about, then, a Japan-Korea (JK) FTA? A JK FTA would cover about $7 \%$ of world trade, about $10 \%$ of global output, and about $3 \%$ of global population. Within the CJK block, the two countries account for about $40 \%$ of combined trade, about $50 \%$ of combined income, and about $12 \%$ of total population (Table 1). Several studies show that a JK FTA would generally be more beneficial to Japan than to Korea with some estimates even pointing towards an absolute decline in Korea's GDP following such an FTA (Scott, 2001; KIEP, 2005; Lee 2006). These studies also point to a further deterioration in Korea's bilateral trade deficit with Japan. Apart from these model-based results, Korea fears that Japanese cars, home appliances, 
and steel products would flood its domestic market. Korea is also concerned about Japan's reluctance to open up its agricultural and fisheries sectors and increase the transparency in Japan's government procurement process (Funabashi, 2010; and Moon, 2010).

In the Korean corporate sector, there is the additional perception that a whole gamut of opaque, Lilliputian, behind-the-border restrictions in Japan are too difficult to comply with for Korean firms to step up their exports to Japan, irrespective of a bilateral FTA. These concerns, perhaps, explain the lack of support for a JK FTA by the Federation of Korean Industries. According to the Korean automobile manufacturers, although Japan allows duty-free car imports, Korean automakers struggle to penetrate the Japanese markets due to a variety of reasons, including the Japanese consumers' preference for homegrown brands and significant non-tariff barriers. Note that in 2012 Korea exported only about 500 automobile units to Japan, whereas Korea imported close to about 20,000 units from Japan. This happened despite the fact that Japan allows duty-free automobile imports while Korea levies an $8 \%$ duty on automobile imports (www.bilaterals.org). Korean automakers thus fear that although they are the biggest beneficiaries of Korea's FTA with the U.S. and Europe, they would not reap a similar benefit from a JK FTA.

Not surprisingly, then, negotiations starting in December 2003 for a JK FTA, after almost five years of joint feasibility studies (between 1998 and 2003), were subsequently suspended after six rounds in November 2004 at the request of Korea (Funabashi, 2010). The negotiations have not resumed, despite Japan's then Prime Minister-Hatoyama - reiterating the importance of a JK FTA. The negotiations could be resumed but that possibility seems somewhat farfetched for the immediate future.

One is then left with the last bilateral option - a China-Korea (CK) FTA. A CK FTA would cover about $12 \%$ of world trade, about $11 \%$ world output, and about $20 \%$ of global population. Within the CJK block, the two countries account for more than $70 \%$ combined trade, more than $50 \%$ of GDP, and more than $90 \%$ of combined population. For Korea, China is the largest trading partner and for China, Korea is the third largest trading partner after the US and Japan. In November 2004, the heads of state of the two countries agreed to conduct unofficial feasibility studies on the CK FTA, and an unofficial study was completed in 2006. As a sequel, the two countries decided to launch an official joint study on the pros and cons of a CK FTA in November 2006 (involving their academia, businesses, and governments).

The official joint study began in March 2007 and five meetings under the study were concluded until June 2008. However, for the next two years not much progress was achieved partly because of the global financial crisis that diverted the attention of their governments to other more pressing issues. However, the two bilateral summits held in 2010 (on April 30 and May 28 respectively) seem to have broken the deadlock, as a CK FTA was an important agenda in both these summits, all the way leading up to the intergovernmental preliminary meeting in September 2010. The two countries further cemented the FTA efforts in early May 2012 when the Trade/Commerce Ministers of both countries agreed to start negotiation for a bilateral FTA. 
Subsequently, five rounds of negotiations have been completed - four in 2012 and a fifth in March 2013. According to the original schedule, the negotiations are to be completed in two years.

All the studies show that a CK FTA would be mutually beneficial to both China and Korea. Most model-simulation-based studies also come to the conclusion that a CK FTA would bring greater macroeconomic benefits to Korea than would a JK FTA (see Scott and Goodrich, 2001; KIEP, 2005; and Lee, 2006). Similar conclusions are derived by looking at export similarity indexes across the three countries, with sectoral export similarity indexes showing that China and Korea's exports in third markets are more complementary to each other than those between Japan and Korea (Lee, 2006). Indeed, a CK FTA is supposed to bring more economic benefits to Korea than could any other FTA that Korea has concluded so far. Estimates show that Korea's GDP could increase by 4 percentage points from a CK FTA as compared to an estimated gain of 3.1 percentage points from a Korea-EU FTA and a 1.3 percentage gain from the Korea-US FTA (Kwon, 2011). Another study by the Korea Institute for International Economic Policy (KIEP) is reported to place Korea's GDP gain in the range of 2-3\% over a ten-year horizon with an additional job creation in the range of 240,000-330,000 (www. bilaterals.org).

Overall, a CK FTA would benefit several Korean industries, especially textile, petrochemical, automobile, semiconductor, and shipbuilding, while benefiting China's agricultural, fisheries, processed food, and clothing sectors (Lee, 2006; Kwon, 2011). Service sectors are another area where Korea can benefit from an entry into the potentially large but currently underdeveloped and undersized Chinese service sector. That said, there are concerns on the Korean side that a CK FTA would put tremendous pressure on their small and medium enterprises from highly competitive Chinese firms, in addition to placing substantial adjustment costs on Korean agricultural and fisheries sectors. It is reported that according to estimates from the state-funded Korea Rural Economics Institute, if agricultural trade is fully freed between China and Korea, Korea's agricultural imports from China would soar by about $\$ 11$ billion and agricultural output could decline by as much as $15 \%$ over the long term (www.bilaterals.org). On the Chinese side, concerns would be mainly focused on the adjustment costs that would be placed on some segments of its emerging manufacturing sectors, such as electronics and machinery.

Overall, it appears that in the negotiations for a CK FTA, agriculture and fisheries are the most sensitive sectors for Korea while some segments of the industrial sector such as electronics and machinery are the most sensitive for China. Hence, although a CK FTA seems to be have the best chance to come to fruition among the three bilaterals, negotiations for a CK FTA will involve some very knotty issues to be skillfully resolved. At a strategic level, it seems that while China has generally preferred to first start negotiations and then work out the sticky details, Korea has shown a preference to narrow down differences before beginning the negotiations (Kwon, 2011). From the Korean side, negotiations with China will proceed in two 
stages: To arrive first at an agreement on the sensitive sectors and afterwards, to get into the other details of the deal. The resistance from the various Korean lobbying groups, especially the agricultural lobby, would perhaps be the single-most important issue to be amicably resolved to ensure that the CK FTA negotiations proceed without undue delays.

\section{Conclusion}

On a balance of considerations, a CJK FTA will not only have large benefits to all the three member countries but it also has the potential to become the building block for the broader multilateral trade and investment liberalization both at the regional and trans-regional levels. From that perspective, the starting of the formal negotiations on the trilateral FTA in recent months, after almost ten years of indecision and inaction on the part of the three Northeast Asian countries, is very encouraging. However, much as there is large merit in a CJK FTA, for various reasons that have been discussed in the previous section of the paper, an expeditious completion of A CJK FTA negotiations seems unlikely. Just as all the three countries have shown a high propensity for indecision and inaction on the CJK FTA in the past decade, they are also likely to show considerable inertia in wrapping up the negotiations. Neither would a bilateral FTA between Japan and Korea (let alone one between China and Japan that is not even at the proposal stage) be any faster to resume and complete than the CJK FTA.

A bilateral FTA between China and Korea, however, has the potential to be expeditiously completed (after having completed five rounds of formal negotiations during the past year), say, in the next year or so. Given these trends and constraints, this paper suggests a dual-track approach to an eventual CJK FTA - a "fast-track route" to an expeditious completion of a China-Korea FTA and at the same time, a "steady-track route" for the completion of a CJK FTA. The former could even have a domino effect on the three countries to hasten the steadytrack negotiations for a CJK FTA. Moreover, each of the partners have something to look forward to in a CK FTA: Korea from manufacturing and service liberalization and China from agriculture, fisheries, and less technology-intensive manufacturing. Certainly, the economic hurdles to a CK FTA appear to be less burdensome than those to a JK FTA. Even though a CK FTA may be more feasible in the immediate future, it will still involve hard negotiations on a number of delicate issues (Kwon, 2011).

Even as the CJK trade and investment cooperation proceeds on a dual-track approach, two issues need to be kept in mind. First, the CJK countries should keep an open mind in joining the two other big multilateral FTAs that are now being negotiated-RCEP and TPPbut at the same time ensure that being part of these multilateral FTAs is not a substitute for a well-designed CJK FTA. The three northeast Asian countries should thus consider the two multilateral FTAs as "CJK-plus initiatives" rather than as "CJK-instead deals". That way, the 
three countries will also contribute to making Asian trade and investment integration truly a process of "open regionalism". Secondly, in designing both the CK bilateral FTA and the broader CJK trilateral FTA, member countries should adhere to at least two basic guidelines: (i) keep the rules of origin as simple as possible to make the FTAs user-friendly (ii) cover substantially all trades to make them WTO-compatible.

If in addition to these two basic guidelines, member countries could also include some of the Singaporean issues, these FTAs would indeed become WTO-plus agreements (ADB, 2008b; Kawai and Wignaraja, 2011). As the former Indonesian Trade Minister Mari Pangestu, who is also a well-known expert on international trade issues, aptly put it: Regional trade agreements should be a "WTO-plus", not a "WTO-instead" (Pangestu, 2011). These FTAs would then really serve as building blocks for the larger and broader multilateral trade and investment liberalization. Hence, the overarching goal of the dual-track approach to the CJK FTA should be one of making the two agreements compatible with the WTO, or even better, making them WTO-plus. More generally, that would really help to make the two "brains" of the emerging global trading system — regionalism and multilateralism—not just coexist with each other but indeed coexist coherently, to paraphrase Pascal Lamy, the former WTO Chief (WTO, 2012, p. 4).

Received 09 October 2012, Revised 30 April 2013, Accepted 05 June 2013

\section{References}

Abe, Katsumoto, (2003), "Economic Effects of a Possible FTA among China, Japan, and Korea", in Yangseon Kim and Changjae Lee (eds), Northeast Asian Economic Integration: Prospects for a Northeast Asian FTA, KIEP Conference Proceedings, pp. 233-263.

Anderson, James E. and Yoto V.Yotov, (2011), "Terms of Trade and Global Efficiency Effects of Free Trade Agreements, 1990-2002", National Bureau of Economic Research (NBER) Working Paper No. 17003, Massachusetts Avenue Cambridge, MA, (April).

Asian Development Bank (ADB), (2011), Institutions for Regional Integration: Toward an Asian Economic Community, ADB, Manila.

ADB, (2008a), Emerging Asian Regionalism: A Partnership for Shared Prosperity, ADB, Manila.

ADB, (2008b), How to Design, Negotiate, and Implement a Free Trade Agreements in Asia, ADB, Manila.

Baldwin R.E., (1995), “ A Domino Theory of Regionalism”, in Baldwin, RE, P. Haaparnta, and J Kiander (eds), Expanding membership of the European Union, New York: Cambridge University Press, pp. 25-53.

Baldwin, R.E. and Dany Jaimovich, (2010), “ARE Free Trade Agreements Contagious?”, NBER Working Paper No. 16084, Massachusetts, Cambridge, MA, (June).

Bergstrand, J. P. Egger, and M. larch, (2009), "Economic Determinants of the timing of Preferential Trade Agreement Formations and Enlargements, University of Note Dame, Working Paper. 
Cheong, Inkyo et al., (2003), Studies on a China-Japan-Korea FTA, KIEP Joint Research Series on FTA Issues.

Crawford, J.A. and C.L. Lim, (2011), "Cast Light and Evil Will Go Away: The First Transparency Mechanism for Regulating Regional Trade Agreements Three Years After”, Journal of World Trade. 45 (2), pp. 375-400.

Dalby, Chris, (2013), "Joining the TPP Best Answer for Further U.S. Encirclement”, Global Times, 8 April (posted on 10 April, 2013, in WWW.Bilaterals.org).

Eichengreen, Barry, (2010), “The Great Recession and the Great Depression: Reflections and Lessons”, Bank of Chile Working Paper No. 593, Santiago (September)

Freund, Caroline. and Emanuel Ornelas, (2010), "Regional Trade Agreements", Policy Research Working Paper No. 5314, World Bank, Washington D.C., May.

Funabashi, Yoichi, (2010), "Japan-Korea FTA Cornerstone of the East Asian Community", East Asia Forum, 20 April.

Gadbaw, Michael R., (2010), "Systemic Regulation of Global Trade and Finance: A Tale of two Systems", Journal Of International Economic Law, 13(3), pp. 551-574.

Gill, Joshua, (2012), "Global Impact of a China-Japan-South Korea Free Trade Agreement”, China Briefing, 29 June.

Gleeson, Deborah and Sharon Friel, (2013), “ Emerging Threats to Public Health from Regional Trade Agreements", Lancet, 1 March, pp. 1507-1509.

Hamanaka, Shintaro, (2012), Anatomy of South-South FTAs in Asia: Comparisons with Africa, Latin America, and the Pacific Islands" ADB Working Paper Series on Regional Economic Integration, No.102, September.

Kawai, Masahiro and Ganeshan Wignaraja, 2011, “Asian FTAs: Trends, Prospects, and Challenges”, Journal of Asian Economics, pp. 1-22.

Korea Institute of International Economic Policy (KIEP), (2005), Rationale for a China-Japan-Korea FTA and Its Impact on the Korean Economy.

Krishna Pravin, (2012), "Preferential Trade Agreements and the World Trade System: A Multilateralist View", National Bureau of Economic Research (NBER) Working Paper No. 17840, Massachusetts Avenue Cambridge, February.

Krugman P, (1991), Is Bilateralism Bad? in E Helpman and A Razin (eds), International Trade and Trade Policy, Cambridge, MA: MIT Press, pp.9-23.

Kwon, Hyuk-jae, (2011), "Free Trade Agreement Between Korea and China", KBS World, 18 April.

Lee, Seoungjoo, (2006), "The Political Economy of FTAs in Northeast Asia: A South Korean Perspective", Paper Presented at the Conference on "Northeast Asia's Economic and Security Regionalism: Old Constraints and New Prospects", Center for International Studies, University of Southern California, 3-4 March.

Madhur, Srinivasa, (2012a), "2 $11^{\text {st }}$ Century Global Economic Governance: Evolving Architecture, Emerging Issues, and Asia’s Role”, 2011 Visiting Scholars' Paper Series, Korea Institute for International Economic Policy, Seoul, pp. 153-191.

Madhur, Srinvasa, (2012b), "Asia’s Role in Twenty First Century Global Economic Governance”, International Affairs, 88:4, July 2012, pp. 817-833.

Menon, Jayant, (2009), "Dealing with the Proliferation of Bilateral Free Trade Agreements" The World Economy, 32 (10), pp. 1381-1407. 
Moon, Sang-Bok, (2010), "Demystifying the Impasse of the Korea-Japan FTA", Journal of international and Area Studies, 17:2, pp-1-19.

Pangestu, Mari, (2011), "No Plan B for Completing Doha", East Asia Forum, 1 June.

Park, Young Bae and Sang-Bok Moon, (2006), Korea's FTA Policy Structure, Mimeo.

Rana, Pradumna B., (2012), “A Region-wide Free Trade Agreement in Asia”, VOX online, 29 June.

Rathus, Joel, (2010), "China-Japan-Korea Trilateral Cooperation and the East Asian Community", East Asia Forum, 15 June.

Ruddy, Brendan, (2010), "The Critical Success of the WTO: Trade Policies of the Current Economic Crisis", Journal of International Economic Law, 13(2) pp. 475-495.

Scollay, Robert and Roman Grynberg, (2005), "Substantially All Trade: Which Definitions are Fulfilled in Practice? An Empirical Investigation", Report for the Commonwealth Secretariat, London, August.

Scott, Jeffrey and Ben Goodrich, (2001), "Economic Integration in Northeast Asia", Paper Presented at the $\mathrm{KIEP} / \mathrm{KEI} / \mathrm{CKS}$ Conference on "Challenges of Reconciliation and Reform in Korea", Los Angeles, California, 24-26 October.

Sim, Edmund W., (2013), "Between China and America? Real Choices Facing Indonesia", Jakarta Global, 22 April (Posted on 22 April 2013 in WWW.Bilaterals.org).

Srinivasan, T.N., (2004), "The Future of the Global Trading System: Doha Round, Cancun Ministerial, and Beyond”, Mimeo, Yale University, New Haven (April).

Wonnacott P and M. Lutz, (1989), "Is There a Case for Free Trade Areas?" in JJ Schott, (ed) Free Trade Areas and U.S. Trade Policy, Washington, D.C.: Institute for International Economics, pp. 59-84.

World Trade Organization (WTO), (2011), World Trade Report 2011 - The WTO and Preferential Trade Agreements: From Co-existence to Coherence, Geneva. 